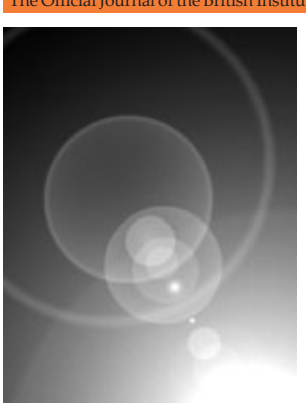

\title{
Relationships of people with learning disabilities in Ireland
}

\author{
Geraldine Bane, Martin Dooher, Josephine Flaherty, Ann Mahon, Padraig Mc \\ Donagh and Marie Wolfe Research into Action, Galway, Ireland; Marie Deely, Rob Hopkins, \\ Ger Minogue and Martin Curry Clare Inclusive Research, Clare, Ireland; and Brian Donohoe \\ and Edel Tierney National Federation of Voluntary Bodies, Dublin, Ireland; Edurne Garcia \\ Iriarte, Siobháin O' Doherty and Stephen Shannon National Institute for Intellectual \\ Disability, School of Social Work and Social Policy, Trinity College Dublin, Dublin, Ireland \\ (E-mail: iriartee@tcd.ie)
}

Accessible summary

\section{Summary}

The inclusive research network is a group of researchers with learning disabilities, their supporters and paid professional researchers who do research about things important to people with learning disabilities in Ireland. In this research, we asked people with learning disabilities what they thought about relationships and supports. We asked people in focus groups: (i) What makes a good friend?, (ii) What do you think about having a boyfriend or a girlfriend?, and (iii) What supports do you need to have friends, a boyfriend or a girlfriend? Ninetyseven people (52 women and 45 men) took part in 16 focus groups. We found that people talked about:

- Wanting to have a boyfriend or a girlfriend.

- Being embarrassed talking about it.

- Needing more support from family and staff to keep relationships and deal with them.

- Wanting more transport to get around at night and to visit people.

- Wanting a house of their own to invite friends, boyfriends and girlfriends.

We talk about the importance of these findings. We also talk about how we have used these findings to advocate for changing the laws in Ireland.

This study explored the perspectives of people with learning disabilities on relationships and supports in the Republic of Ireland. A national research network consisting of 21 researchers with learning disabilities, 12 supporters, and 7 university researchers conducted the study. Researchers with learning disabilities and their supporters ran 16 focus groups with peers with learning disabilities. A total of 97 adults with learning disabilities from across the country took part in the focus groups. Findings suggest that people with learning disabilities have a diversity of experiences and views on relationships and support needed to keep them. People with learning disabilities taking part in the focus groups identified that they need more support from friends, family, and services staff to develop new relationships and keep their existing ones. This support includes both emotional and systematic changes such as accessible transport, own housing, and changed laws. The article discusses how the research team used the findings to advocate 
for a change in the laws concerning sexuality and learning disability in the Republic of Ireland.

Keywords Learning (intellectual) disabilities, research, sexuality

\section{Introduction}

This study is about relationships of people with learning disabilities in Ireland. In the past, researchers have asked staff and families what they think about relationships of people with learning disabilities.
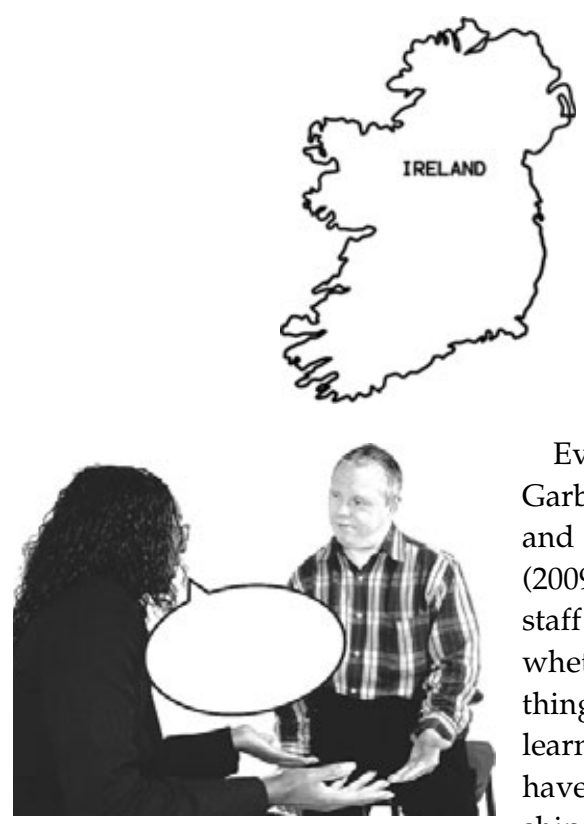

Evans et al. (2009), Garbutt et al. (2009) and Tattersall et al. (2009) have found that staff are not sure whether it is the right thing for people with learning disabilities to have intimate relationships. They also said that staff need more training and guidance on how to support people with learning disabilities to have relationships.

Evans et al. (2009) found that staff in general are more supportive than families towards intimate relationships of people with learning disabilities.

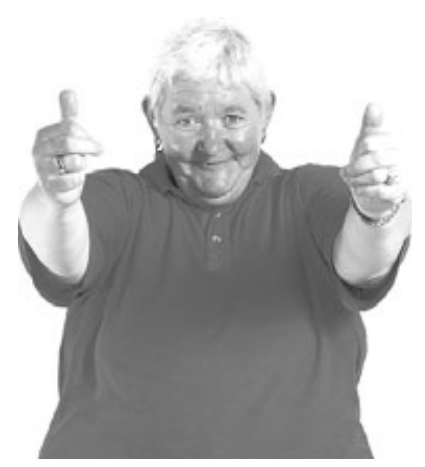

However, when researchers have asked people with learning disabilities about relationships, they have found out that: (i) people with learning disabilities know it is their right to have them, (ii) they want to exercise choice in the relationships they have and (iii) they want control over the type of support they need (Kelly et al. 2009; National Institute for Intellectual Disability 2009).

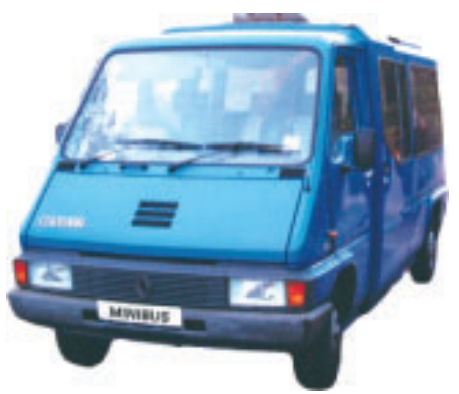

People with learning disabilities have said that to keep friends and be independent they needed:

1. Better access to transport.

2. More chances to meet with friends.

(Healy et al. 2009; Tattersall et al. 2009).

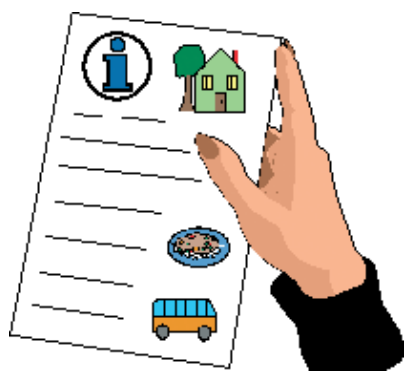

Researchers have found that it is important that accessible information about topics such as sexuality, pregnancy and sexual health should be easily available to people with learning disabilities (Kelly et al. 2009; Tattersall et al. 2009). This information should be given to young people in particular (Healy et al. 2009; Kelly et al. 2009; Tattersall et al. 2009).

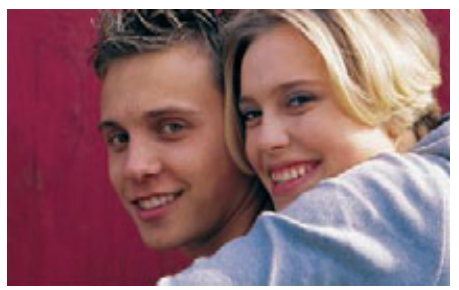


Furthermore, people with learning disabilities may need support to feel comfortable about showing their sexuality in a safe way (Healy et al. 2009; Kelly et al. 2009; Tattersall et al. 2009).

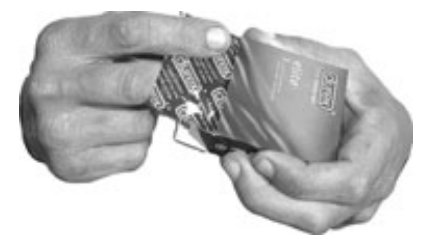

Some researchers have pointed out the importance of sex education training for people with learning disabilities (Healy et al. 2009; Tattersall et al. 2009).

Finally, Kelly et al. (2009) said that in Ireland, people with learning disabilities need support to have their voices heard by government.

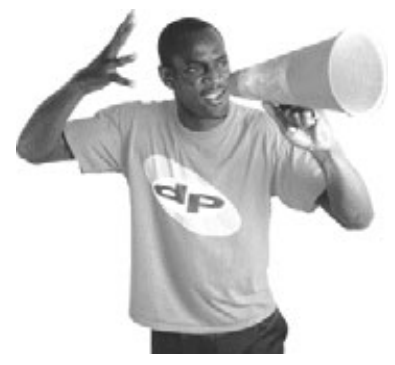

In conclusion, it was found that people with learning disabilities want to have control over their relationships but may need education and support such as transport and accessible information.

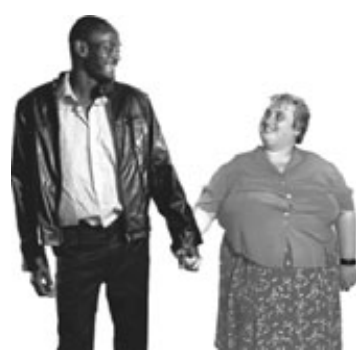

This study is about what people with learning disabilities in Ireland thought about friendships and relationships and the support they needed to have them and keep them.

These were important questions to ask because the laws in Ireland make it difficult for people with learning disabilities to have sexual relationships. In addition, these questions had not been asked before in Ireland by researchers with learning disabilities. This was the first study about relationships in Ireland that included people with learning disabilities as researchers. Members of the Inclusive
Research Network (IRN) did this study. A summary of the laws in Ireland and a description of the IRN follow.

\section{Ireland}

The Irish laws dealing with sexual relationships are an important reason to do this study.

Ireland signed the United Nations Convention on the Rights of Persons with Disabilities in2006. We will call it the Convention in this article.

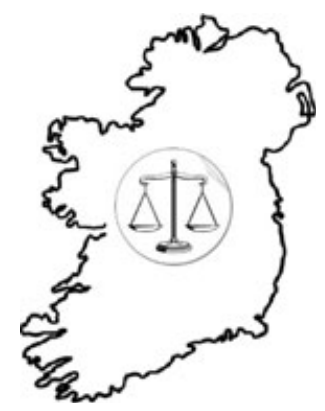

Article 23 of the Convention says that:

1. People with learning disabilities have the right to get married, have children and have sexual relationships.

2. By signing the Convention, the Irish government is committed to make this happen.

Article 12 of the Convention says that people with learning disabilities must be allowed to make their own decisions.

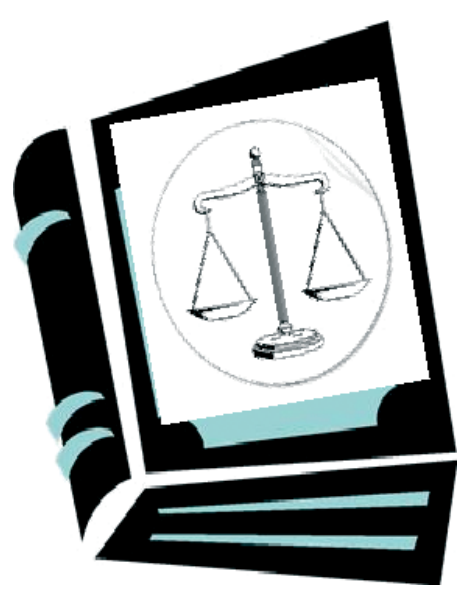

However, according to the National Disability Authority (2009) and Inclusion Ireland (2009) that speak up for the rights of people with disabilities, there are two laws in Ireland that make things difficult for people with learning disabilities to:

1. Have sexual relationships and

2. Make decisions about them. 


\section{The Criminal Law (sexual offences) Act of 1993}

This law says it is not legal to have sex with a person with a learning disability who cannot live an independent life (Government of Ireland 1993).

\section{The Lunacy Act of 1871}

This law says that for some people with learning disabilities, others have the power to make all the important

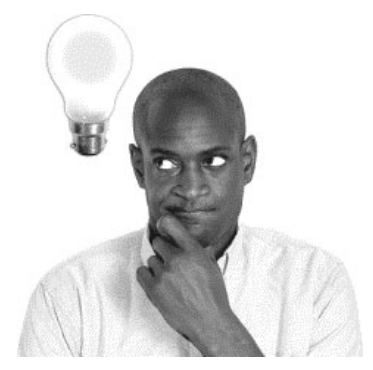

decisions in their life, including getting married (UK Parliament 1871).

Some people have suggested a new law about making decisions, the Mental Capacity Bill (Department of Justice \& Law Reform 2008). This law would allow people with learning disabilities to make more of their own decisions, including those about relationships.

\section{The IRN}

The IRN is a group of researchers and supporters from all over Ireland. All members have research experience. Some have learning disabilities, some have experience supporting people with learning disabilities to conduct research and some are paid professional researchers. This group was started in 2008. To find out more about it, you can read the report by Tierney et al. (2009).

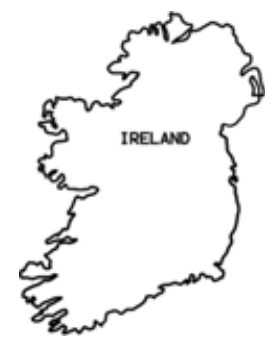

The IRN does research about things that are important to people with learning disabilities, for example places where we live and relationships. The studies the IRN has carried out are called Where we Live (Inclusive Research Network 2009) and Relationships and Supports (Inclusive Research Network 2010).

The IRN members work as a team doing research tasks. These include

1. Think about the research topic.

2. Choose the research questions.

3. Get the data (doing interviews, running focus groups, doing surveys).

4. Write up the research reports.

5. Present the results of the research at conferences.

The IRN members meet at 1-day workshops. In the workshops, members:

1. Talk about research they do.

2. Do training on how to do research.

3. Present research projects.

The IRN believes research is good because members learn new information and ideas. It helps members with public speaking and listening, it gives them something to do and they learn from each other.

The IRN is sponsored by the National Institute for Intellectual Disability and the National Federation of Voluntary Bodies. The authors of this article are all IRN members and are referenced as 'we' in the following pages.
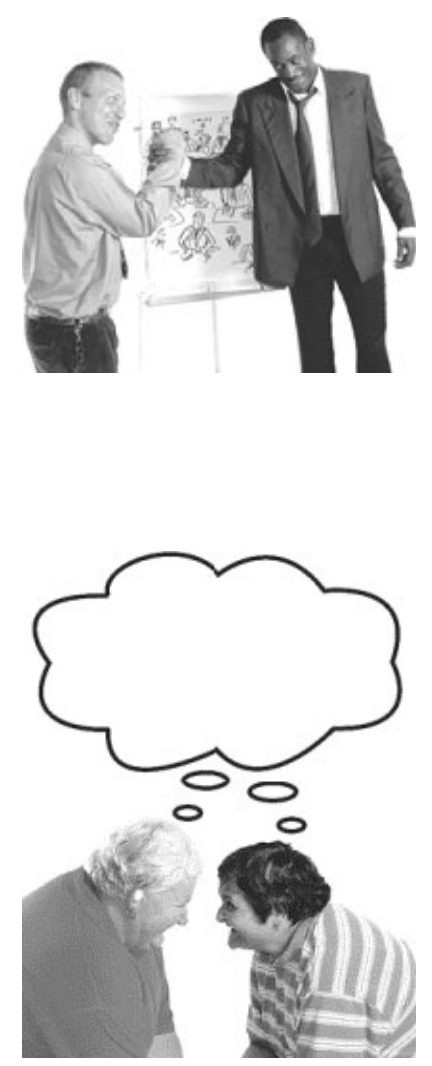


\section{Method}

In this section, we talk about the IRN training on research methods, ethical approval and focus groups.

\section{Training on research methods}

To learn how to do this research, we had training workshops in two cities in Ireland.

There were 47 people at the training workshops:

1. 32 were researchers with learning disabilities.

2. 15 were supporters including paid professional researchers.

At the training workshops, we learned how to:

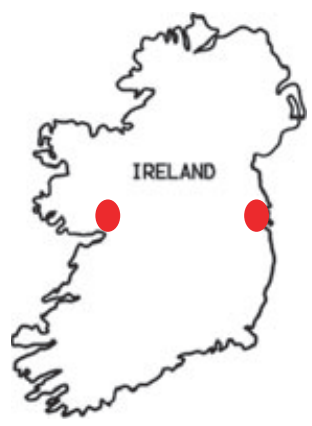

1. Recruit people for the focus group.

2. Ask for consent from those taking part.

3. Run the focus group.

4. Ask questions.

5. Get people to take part in the focus group.

6. Support people to take part.

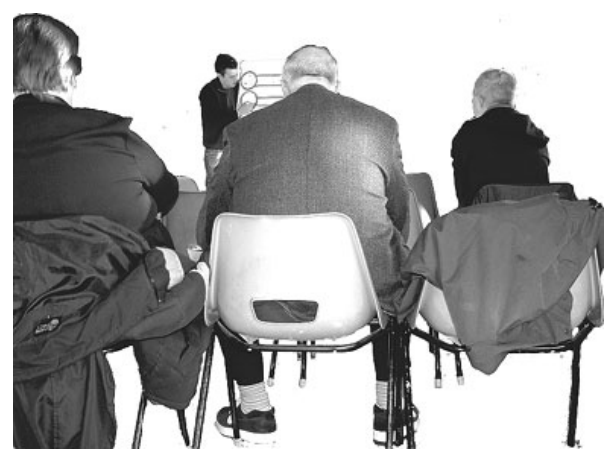

\section{Ethical approval}

The paid professional researchers applied for and received ethical approval for the study from their university's ethics committee.

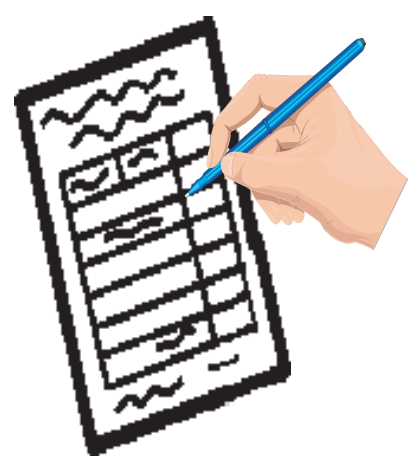

In the application for ethical approval, the paid professional researchers who worked at the university explained:

1. The purpose of the study and research questions.

2. The research methods.

3. How we would respect the rights of people with learning disabilities taking part in the study by:

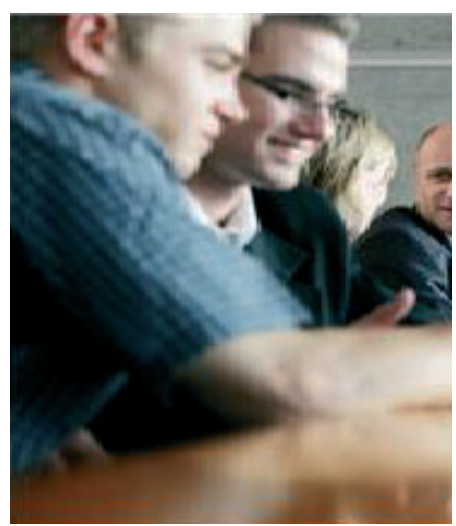

- Sharing the information about the study - we used information forms

- Getting informed consent from participants - we used consent forms.

Although the issues addressed in the application were discussed between paid professional researchers, researchers with learning disabilities and supporters, only paid professional researchers completed the application.

\section{Information forms}

1. These forms had information about what the study was about, what would happen during the study and the rights of participants taking part:

- Information from participants would be kept private

- Participants could stop taking part at any time

- If a participant became upset during a focus group, they could talk to a social worker, support worker or someone of their choice. 


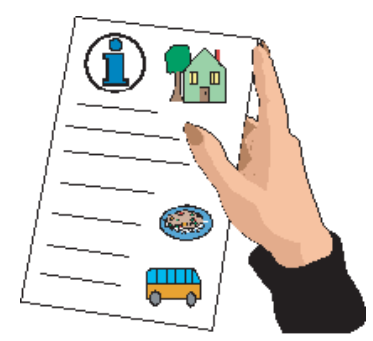

There were information forms for:

1. People taking part in the focus groups.

2. Supporters.

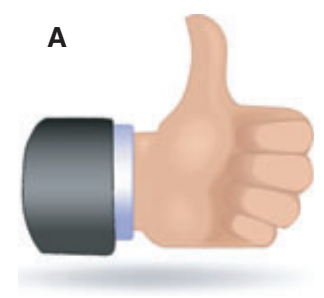

3. Organisations

4. Family members.

Before the focus groups took place, each of the researchers with learning disabilities invited people with learning disabilities from service organisations and self-advocacy groups to take part in the research.

If people said they were interested in taking part, the researchers with learning disabilities sent them information forms about the study.

\section{Consent forms}

The consent forms were like a contract. People taking part only signed the consent forms when:

1. They knew what the study was about.

2. They were happy to take part.

By signing the consent form, they agreed:

1. To take part.

2. To allow the focus group to be recorded.

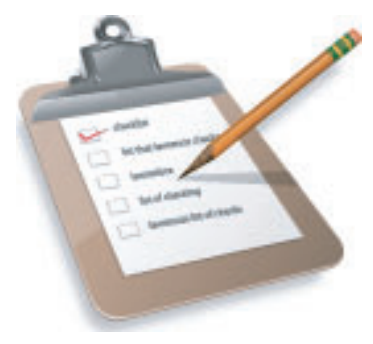

\section{Focus groups}

Twenty-two of the researchers with learning disabilities facilitated 16 focus groups in a number of locations in Ireland. 12 supporters worked with them. Researchers with learning disabilities and supporters used handbooks as a guide to organise and run the focus groups.

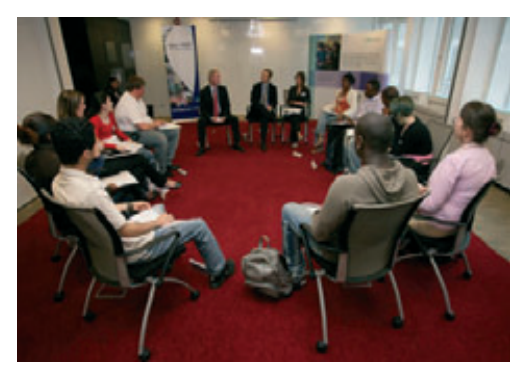

There were two different handbooks:

1. One for the researchers with learning disabilities on how to recruit participants and facilitate focus groups.

2. One for the supporters on how to work with researchers with learning disabilities during the research study.

The focus groups discussed 3 questions:

1. What makes a good friend?

2. What do you think of having a boyfriend or a girlfriend?

3. What support do you need to have a friend, a boyfriend or a girlfriend?

The researchers with learning disabilities facilitated the focus groups.

Each researcher had a supporter with them to:

1. Record the focus group.

2. Write down the answers to the questions on flip charts.

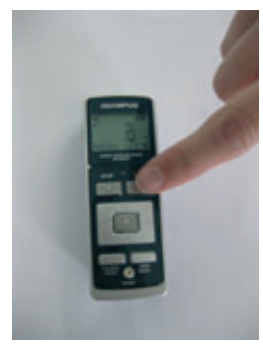

Supporters also helped by:

1. Repeating the questions.

2. Helping people understand and follow the discussion.

3. Writing notes. 


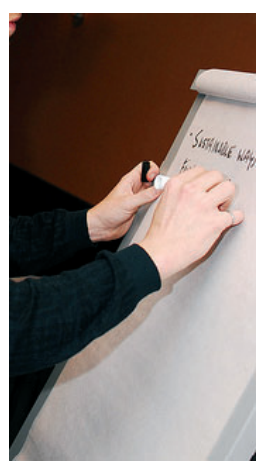

Supporters agreed that researchers with learning disabilities were the ones doing the research. They agreed to support them only when they asked or if they did not follow the guidelines. The focus groups were then transcribed by the paid professional researchers.

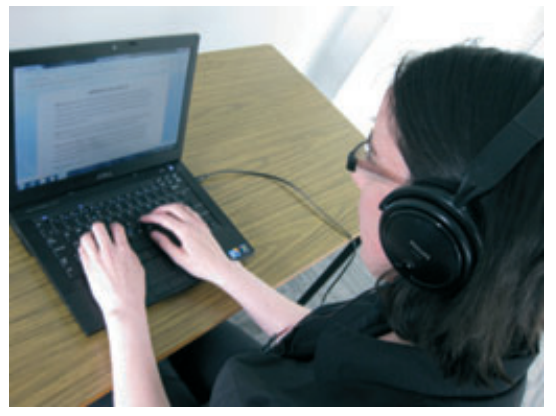

\section{Participants}

Ninety seven people took part in the focus groups. They were from all around Ireland:

- 45 men and 52 women.

- 42 people over 30 .

- 17 people under 30.

- Some people did not tell us their age.

- All of these people had a learning disability.

\section{Analysis}

The paid professional researchers did the first round of analysis. They:

1. Used themes to explain important things that people talked about in the focus groups.

2. Made a summary of all the themes with one picture and one quote to give an example of a theme.
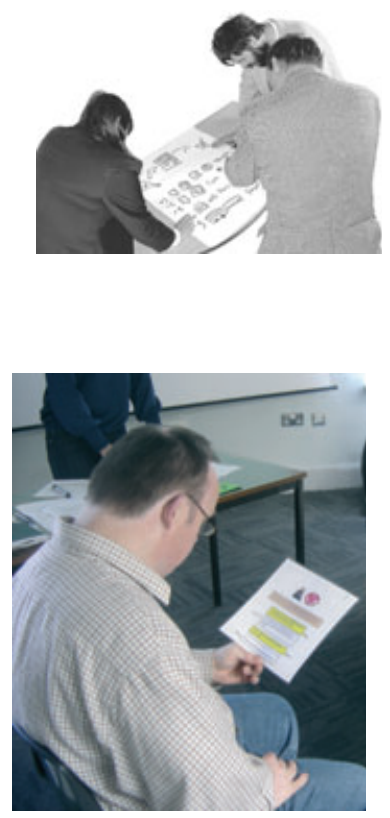

3. Sent the summary to all the researchers with learning disabilities and their supporters and asked them to:

- Read the summary.

- Compare the summary with what people in their focus group had discussed.

A group of researchers with learning disabilities, supporters and paid professional researchers met to discuss the summary. We did role plays to explain the themes. We asked these questions in the meeting:

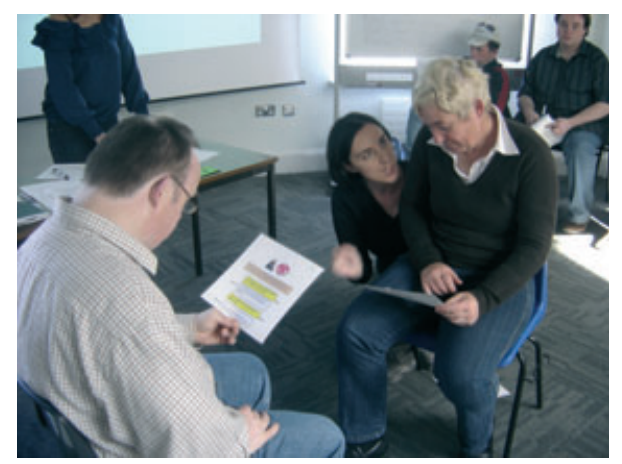


1. Is this a good summary?

2. Is this what people said in the focus group?

3. Is there a better way to do a summary of what people said?

4. Is there anything else that people said?

These were the conclusions of the meeting:

1. The summary of themes should answer clearly the research questions.

2. Education was also a support to have relationships, although people did not talk about that in the focus group.

3. Some of the themes should have different names, for example:

- Treats you well' should be called 'treat each other well'.

All the themes were reviewed by the paid professional researchers taking into account this feedback.

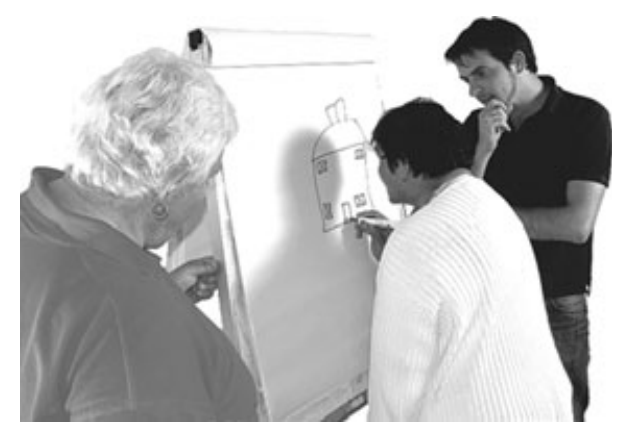

\section{Results}

These are the responses that people gave us in the focus groups about what makes a good friend, what they thought about having a boyfriend or a girlfriend and what supports they needed to have friends, boyfriends and girlfriends.

\section{Having a good friend}

When asked 'What do you think makes a good friend?' they said:

1. 'It's someone who will be there for you'

2. 'Someone who looks out for you'.

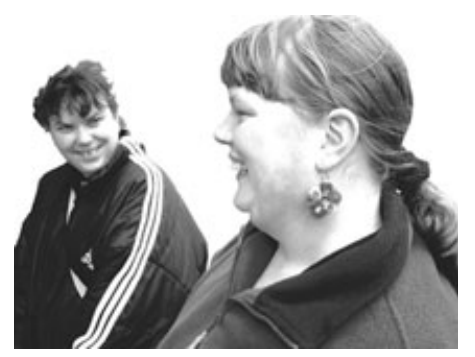

Another answered that:

- It is someone you can do things with, like 'going swimming or going to the pictures'.
Our research showed that some members of the focus groups were unsure if they were a couple or 'just friends'.

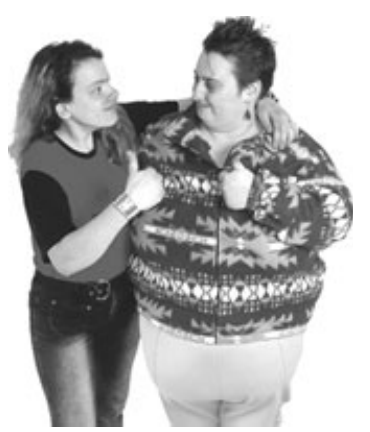

Some people were concerned that their parents were sometimes too strict. One said:

- 'My parents are a bit unfair about letting me out with my friends and stuff'.

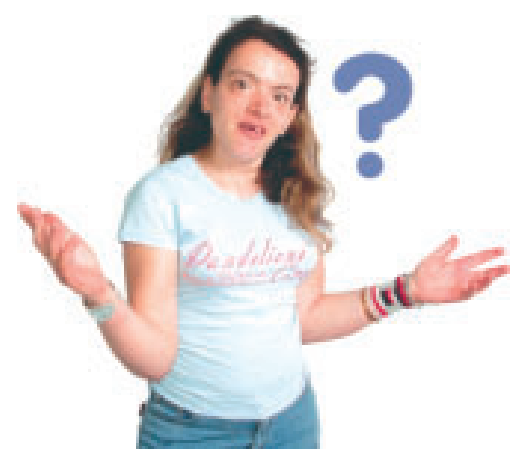

Overall, most people in the focus groups were sure that a good friend is there for you but sometimes people were unsure how a friend was different to a boyfriend or a girlfriend. In addition, people felt they were not treated fairly when they wanted to see their friends.

\section{Having a boyfriend or a girlfriend}

People talked about what they thought were the nice parts of having a boyfriend or a girlfriend:

1. 'It is nice to be boyfriend or girlfriend'.

2. 'It's important to treat each other well and do things together'.

3. 'Go on walks and things like that, go to bookshops. All those things'.

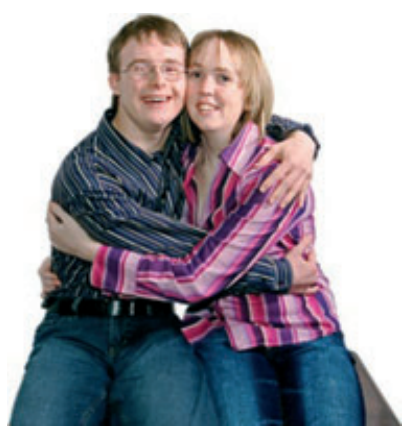


People talked about loving one another. One said:

- 'It's good to have a boyfriend because they care about you and cuddle and snuggle and mind you and help you and stuff like that'.

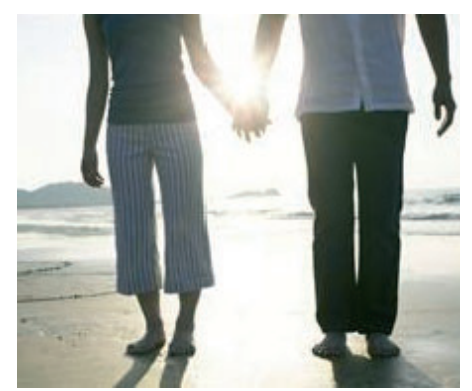

Some people talked about the importance of dating and being romantic.

Some members said that they had experience of relationships. Others said they did not know what a boyfriend was or what to do with him. For example, one said:

- 'Well, I don't know what a boyfriend is. If I went out with Sean I wouldn't know what to do with a boyfriend'.

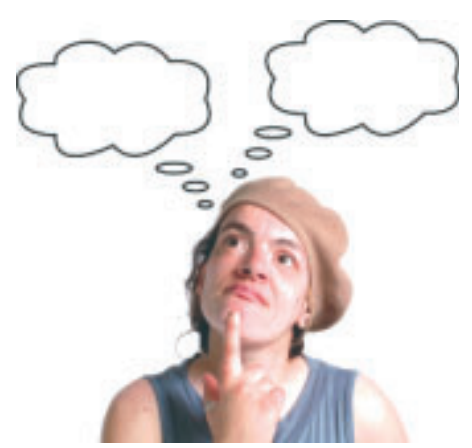

For some people having a boyfriend or a girlfriend could be embarrassing. Some people felt embarrassed to ask someone out. For example,

- 'When you're talking about that we're getting embarrassed'.

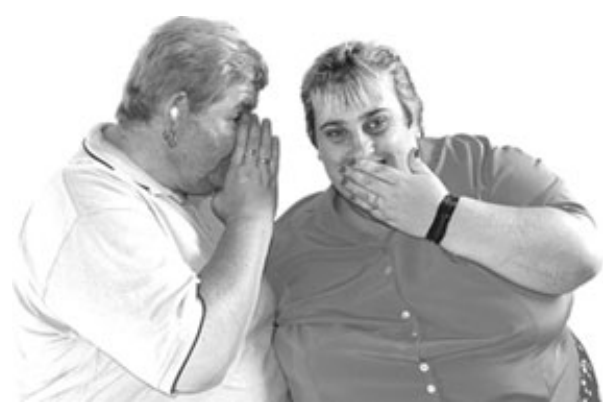

Some people had traditional expectations of men in relationships. One person said that they expected the man to be the one to ask the woman out on a date. One said:

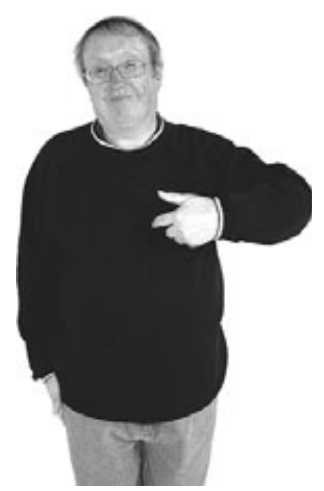

- 'That job is up to the boy'.

Others expressed that they did not have a relationship but would like one, for example:

- 'I wish I had one. I had one and I broke up from him'.

One reason people found it hard to have relationships was that, in general, they felt they were treated like children. One said:

- 'May be people have different attitudes to other people that have a disability and people are in wheelchairs and they can't have a boyfriend.... You're kind of looked down on. You're kind of treated like children'.

For some, having a boyfriend or a girlfriend was not important. However, others felt left out because they did not have a partner, for example:

- 'I have a lot of friends around me that have a boyfriend or girlfriend. I'm the only person in the house that doesn't have a boyfriend and everyone has a boyfriend at home so I can feel I'm out of the picture'.

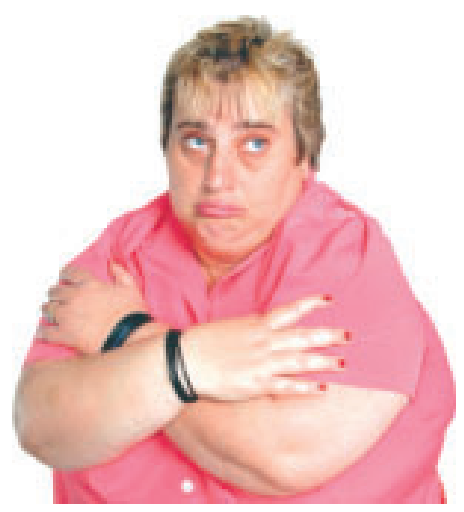

Others expressed that they would like to get married and felt it was up to themselves if they wanted to get married. One said:

- 'It's our choice if we want to get engaged or married. It's up to us'. 


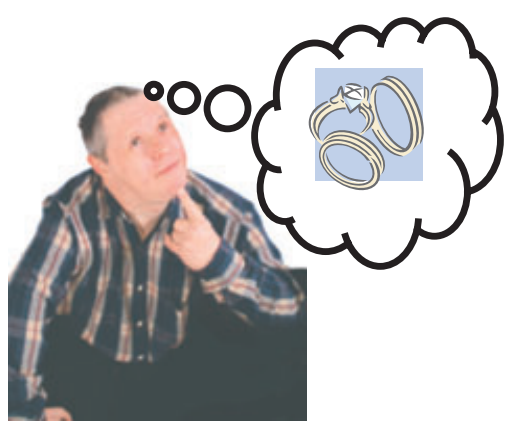

\section{Support}

People in the focus group talked about support from staff and families. Some people in the focus groups were aware that support from staff often depended on funding. For example:

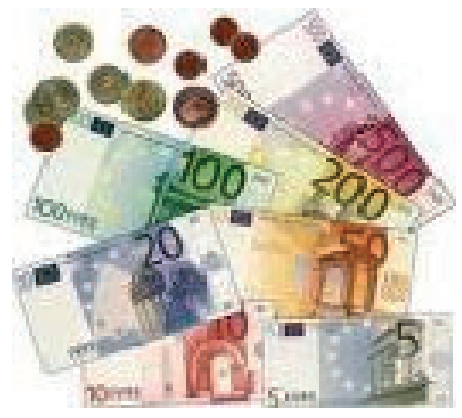

- 'Well, I would like to get to go out a lot more. To get to know a lot more new friends... it's because of the funding of staffs. The money is not there for that'.

Some people felt that it was important to have staff to talk to about relationship problems. People also said that families had a role to play. For example, one said that families could be there to give support, particularly after breaking up with someone:

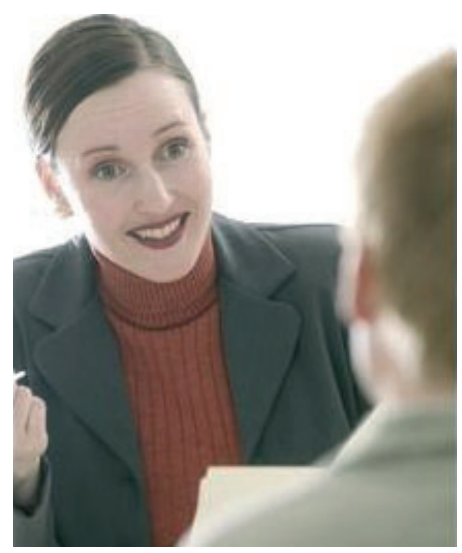

- 'Can help you through everything... if you're going through a rough time'.
People also talked about other things that were important in supporting them to have and keep friends, boyfriends and girlfriends.

One of these things was access to public transport. For example, one person said:

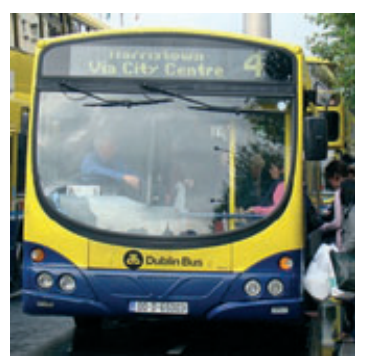

- 'Me and Carol are trying to use public transport more often so that we can use it if we get a chance to go out on a night somewhere'.

Having their own accommodation was important to people in getting and keeping friends, boyfriends and girlfriends. One person, for example, said it was important to:

- 'Get your own place. Get your own house'.

Others expressed the wish to live as a couple and get their house together.

Overall, people in the focus groups had similar ideas about what a good friend was. They had different ideas

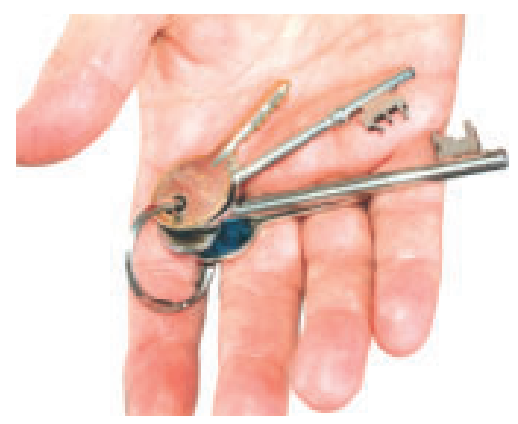

about what it meant to have a boyfriend or girlfriend. Some people wanted a boyfriend or girlfriend and some people did not. Staff, family and transport were named as key in providing support to people in getting and keeping friends, boyfriends and girlfriends.

\section{Discussion and recommendations}

For the first time, we, as people with learning or intellectual disabilities in Ireland, have begun producing our own research about relationships in the last decade. We discuss here our study findings and recommendations. 


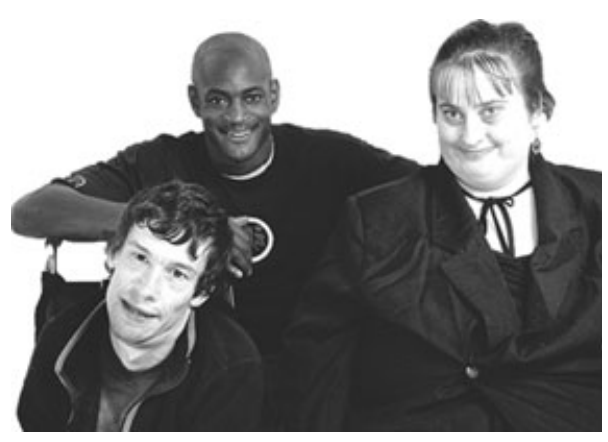

Our research says that friendships and relationships are very important. Good friends, for example, can look out for each other and give each other encouragement.

We found that people with a learning disability know about their rights to have relationships as the Convention states.

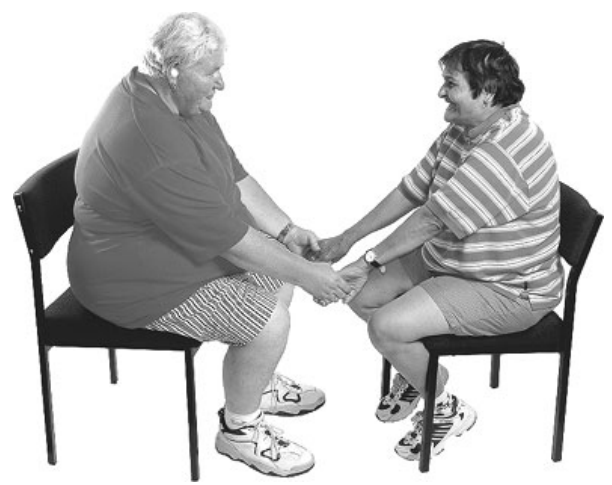

They want to be making decisions about their relationships. Similar conclusions have been reached by other studies conducted in Ireland (National Institute for Intellectual Disability 2009).

We found that people with learning disabilities sometimes want the support from families, parents, friends and staff to have and keep their friendships and relationships.

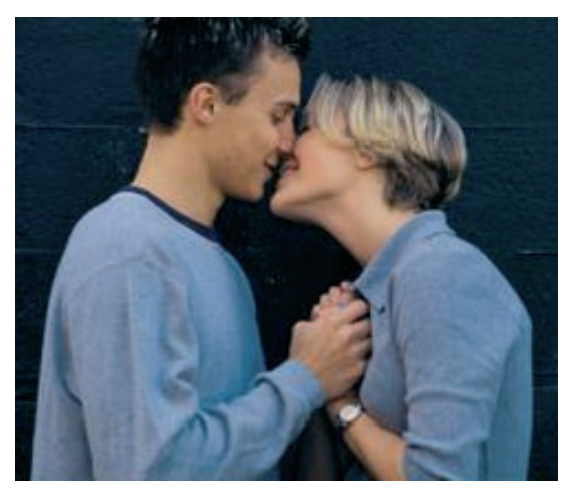

However, we found out in the research that people feel they are treated like children regarding relationships. Evans et al. (2009) and Tattersall et al. (2009) found that staff needed more training and guidance on how to support people with learning disabilities to have relationships. The findings of our research indicate that this training and guidance should include viewing adults with learning disabilities as adults with rights.

Healy et al. (2009) and Tattersall et al. (2009) have found that it is important that people with learning disabilities have sex education training. We did not find that in our research.

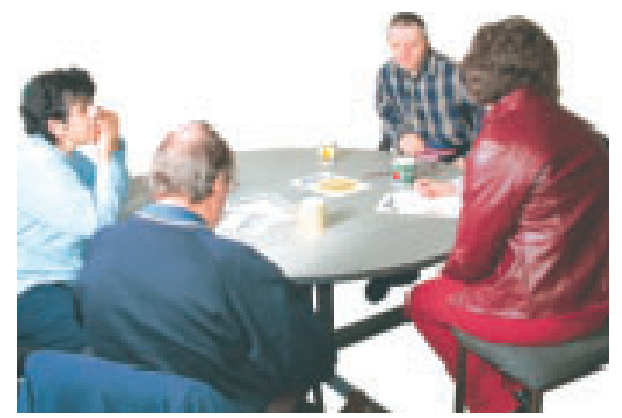

However, when we discussed the findings, we suggested that education on relationships would help people with learning disabilities to have relationships. This would help clarify some of the things people in our research were confused about. For example, some people did not know the difference between friends and boyfriends or girlfriends; some people thought that asking out was the responsibility of men; finally, nobody talked in the focus groups about same sex relationships. These themes may reflect common perceptions about relationships in rural Ireland and the need for people with learning disabilities' education on relationships.

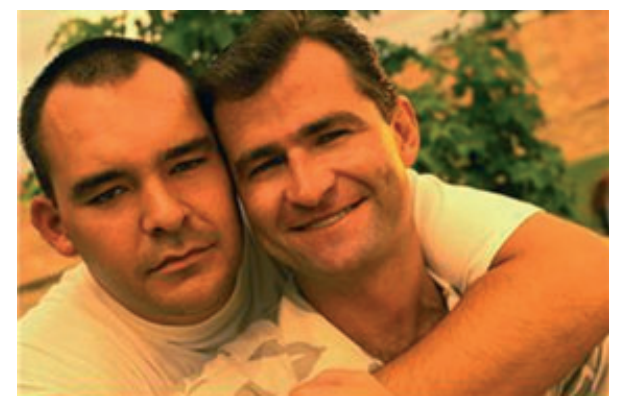

Regarding support to have and keep relationships, we found similar things to Healy et al. (2009) and Tattersall et al. (2009). For example, people expressed in our research that they needed to have better access to public transport to have and keep relationships. We also found that for people with learning disabilities, having their own accommodation was important to keep relationships.

Kelly et al. (2009) recommended people with learning disabilities are supported to have their voices heard by 


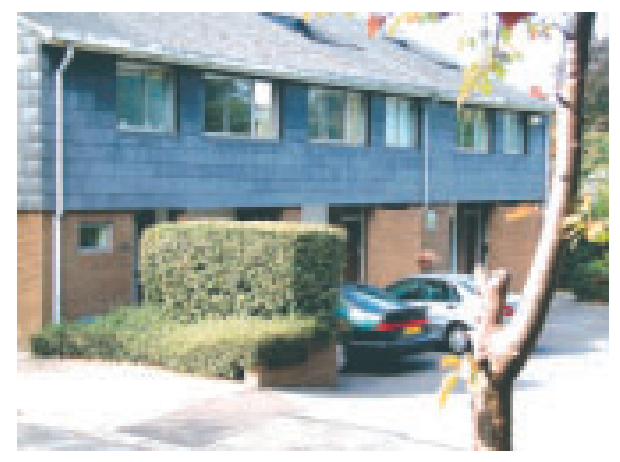

government. Because we conducted this research, we were invited to a meeting with the Law Reform commission in Ireland to talk about making changes to the Criminal Law (Sexual Offences) Act 1993.

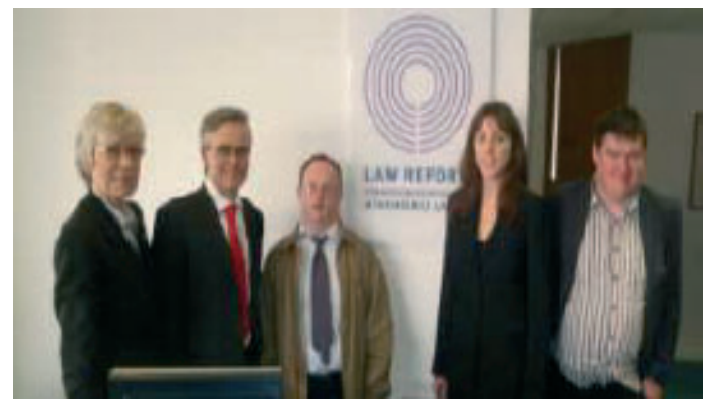

We presented what our research said about people with learning disabilities and relationships. We felt more confident speaking about it after conducting the research. This meeting also included service providers, managers, social workers and psychologists.

Because we wanted more people to understand what the law says about us we talked about how the Criminal Law Sexual Offences Act was written.

We said the Law should use everyday language. We said words like 'gross indecency' was confusing, that 'buggery' was a very offensive word and that 'mentally impaired' and 'disorder of the mind' were disrespectful and totally unacceptable.

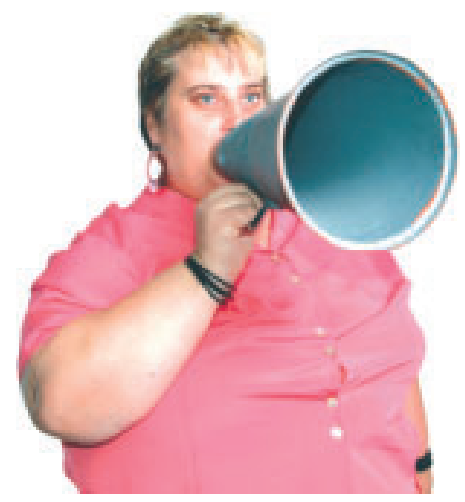

It was explained to us by the Commissioner that the heads of a new capacity bill have been passed and that a new law was being written and they valued our help.

A Law Reform Commission legal researcher wrote to us after the consultation,

'It was a great opportunity for us to hear the practical difficulties facing.... people who are directly affected by Section 5 of the 1993 Act.'

The Commission said they would like to talk with us again to look for our opinions on their recommendations.

Doing the research gave us knowledge about what other people with learning disability think in Ireland and great confidence to speak about these things to people.

Hopefully, other people with learning disabilities will hear about these findings and get involved in doing research. It is changing the way people think about learning disability.

\section{Recommendations}

Based on this study findings, we recommend:

1. People with learning disabilities get involved in doing research about relationships.

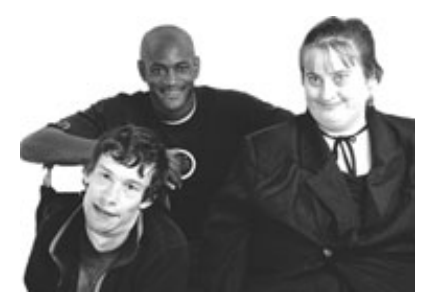

2. More people with learning disabilities are supported and encouraged to use public transport independently. For that, we further recommend that:

a. Public transport authorities involve people with intellectual disabilities in the design of accessible transportation services.

b. Public transport personnel are educated on accessibility of public transportation.

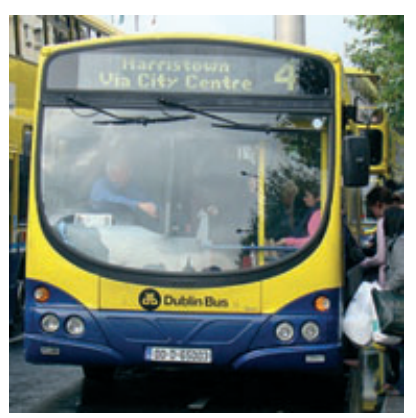


3. People with learning disabilities should be involved in the training of staff and families on the rights of people with learning disabilities to have relationships.

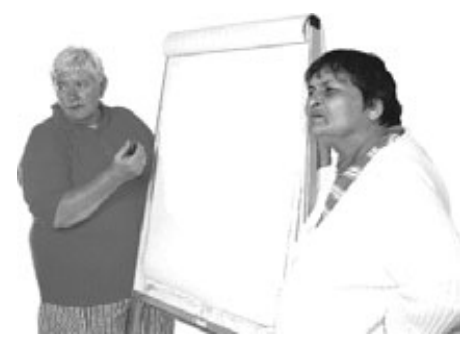

4. Information on sexual relationships should be accessible and available to people with learning disabilities. This should include policies, regulations and general information.

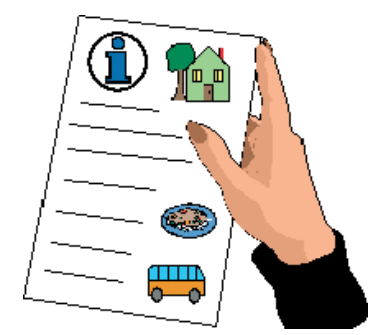

5. Changing the law, because people with learning disabilities in Ireland should have the same right as everyone else to have intimate relationships.

\section{Acknowledgements}

All the authors are part of the Inclusive Research Network that is co-sponsored by the National Institute for Intellectual Disability, Trinity College Dublin, and the National Federation of Voluntary Bodies, Ireland. This research was partly funded by a Marie Curie Transfer of Knowledge Fellowship to the National Institute for Intellectual Disability, Trinity College Dublin, within the 6th European Community Framework Programme. The views expressed herein are those of the authors and not necessarily those of the 6th European Community Framework Programme. All images used are from the CHANGE picture bank.

\section{Note}

All names used in the findings section are fake names.

\section{References}

Department of Justice and Law Reform, 2008. Scheme of Mental Capacity Bill. Available at: http://www.justice.ie/en/JELR/ Scheme\%20Mental\%20Capacity\%20Bill.doc/Files/Scheme\% 20Mental\%20Capacity\%20Bill.doc (last accessed on 26 June 2011).

Evans D.S., McGuire B.E., Healy E. \& Carley S.N. (2009) Sexuality and personal relationships for people with an intellectual disability. Part II: staff and family carer perspectives. J Intellect Disabil Res, 53(11): 913-21.

Garbutt R., Tattersall J., Dunn J. \& Boycott-Garnett R. (2009) Accessible article: involving people with learning disabilities in research. Br J Learn Disabil, 38(1): 21-34.

Government of Ireland, 1993. Criminal Law (Sexual Offences) Act. Available at: http://www.irishstatutebook.ie/1993/en/act/ pub/0020/index.html (last accessed on 26 June 2011).

Healy E., McGuire B.E., Evans D.S. \& Carley S.N. (2009) Sexuality and personal relationships for people with a learning disability. Part I: service-user perspectives. J Learn Disabil Res, 53(11): 905-12.

Inclusion Ireland, 2009. Capacity and Guardianship. Available at: http://www.inclusionireland.ie/documents / CapacityFactsheet09.pdf (last accessed on 26 June 2011).

Inclusive Research Network, 2009. Where we live: A national study done by members of the Inclusive Research Network through surveys. Dublin: National Institute for Intellectual Disability Ireland. Galway: National Federation of Voluntary Bodies. Available at: http://www.tcd.ie/niid/pdf/IRN revised folder/PDFs/where we live Report 2010.pdf. (last accessed on 16 April 2012).

Inclusive Research Network, 2010. Relationships and Supports Study: People with Intellectual Disabilities in Ireland. Dublin: National Institute for Intellectual Disability, Ireland. Galway: National Federation of Voluntary Bodies. Available at: http:// www.tcd.ie/niid/pdf/IRN revised folder/PDFs/ Relationships and Supports Report 2010.pdf. (last accessed on 16 April 2012).

Kelly G., Crowley H. \& Hamilton C. (2009) Rights, sexuality and relationships in Ireland: 'It'd be nice to be kind of trusted'. $\mathrm{Br} J$ Learn Disabil, 37(4): 308-15.

National Disability Authority, 2009. NDA Submission on capacity and sexual relations in the context of the mental capacity scheme of bill. Available at: http://www.nda.ie/Website/ NDA/CntMgmtNew.nsf/0/ 66292BBCC27B2914802575B7003D5E83?OpenDocument (last accessed on 26 June 2011].

National Institute for Intellectual Disability, 2009. All we want to say: Life in Ireland for people with learning disabilities. Dublin: Trinity College Dublin. Available at: http://www.tcd.ie/niid/ research/projects/Allwewanttosay.php.

Tattersall J., Boycott-Garnett R., Garbutt R., Dunn J. \& Durbali R. 2009. Talking About Sex and Relationships: The views of young people with learning disabilities. The final report of the sexuality project by CHANGE 2007-2010. Leeds: Centre for Disability Studies, Leeds University.

Tierney E., Curtis S. \& O' Brien P. 2009. The inclusive research network. A participatory action research project. Dublin: National Institute for Intellectual Disability Ireland. Galway: 
National Federation of Voluntary Bodies. Available at: http:/ / www.tcd.ie/niid/research/irn/.

UK Parliament, 1871. Lunacy Regulations (Ireland) Act. Available at: http://www.opsi.gov.uk/acts/acts1871/pdf/

ukpga_18710022_en.pdf (Accessed on 26 June 2011).
United Nations, 2006. UN Convention on the Right of Persons with Disabilities. Available at: http://www.un.org/disabilities/ documents/convention/convoptprot-e.pdf (last accessed on 26 June 2011). 
Copyright of British Journal of Learning Disabilities is the property of Wiley-Blackwell and its content may not be copied or emailed to multiple sites or posted to a listserv without the copyright holder's express written permission. However, users may print, download, or email articles for individual use. 